diagnosis. In this patient it was positive, probably because the disease had remained latent for so long.-I am, etc.,

\section{J. VAFRMAN}

achieved.-I am, etc.,

Westminster Hospital.

J. K. OATES London S.W.1

Infectious Diseases Unit,

Western Hospital,
London S.W.6

1 Wolff, C. B., Goodman, H. V., and Vahrman, J., British Medical fournal, 1970, 2, 271.

\section{Gonorrhoea in the Family}

SIR,-With the current high incidence of gonococcal infection I feel the following account might be of interest.

A $6 \frac{1}{2}$-year-old girl developed a vaginal discharge and as a result was referred by her general practitioner to the casualty department, where a vaginal swab eventually produced a growth of gonococci. She was given a course of ampicillin $250 \mathrm{mg}$ sixhourly for five days. At the end of this time a repeat swab was negative for the gonococcus and the child was referred to the venereal disease clinic for follow-up.

When she attended there was clinical evidence of vulvovaginitis, though smears were negative for the gonococcus. The mother was incensed when it was suggested that she should be examined, and it was only after the possible routes of infection in her daughter's case were explained to her that she consented. She was four months pregnant and had no symptoms such as vaginal discharge or dysuria. She had recently remarried and denied sexual relations with anyone other than her present husband for the last two years. On examination she had minimal evidence of cervicitis but no gonoccoci could be found in the smears. She agreed to attend again in two days' time with her husband.

She duly appeared and by this time the cultures were positive for the gonococcus in both cervix and urethra. The daughter was re-examined and smears from the vagina now showed gonococci to be present. The husband, who accompanied his wife, was interviewed, and said that he had no symptoms at all and denied sexual relations with anyone other than his wife for a period of 18 months. On examination he had no urethral discharge and the urine was quite clear after being held for two and a half hours. A scrape from the meatus before passing urine, however, showed many typical negative diplococci, both extracellular and inside pus cells.

The source of the infection remains a mystery as is so often the case with this disease. Nevertheless, the story serves to illustrate the following characteristics of gonorrhoea :

The disease is nearly always a mild one if not wholly latent in women. This latency does not protect women (or children) from the serious complication of salpingitis, which develops in about $10 \%$ of all patients.

That true latency can also occur in men is not so well known but it is familiar to every venereologist and may indeed be commoner than is generally supposed.

Gonococcal vulvovaginitis in a child should always lead to an examination of the parents.

Gonococcal vulvovaginitis in a child is frequently difficult to cure, and careful follow-

\section{Treatment of Paraquat Ingestion}

SIR,-Clark ${ }^{1}$ found that Fuller's Earth and gastrointestinal tract of animals, inhibiting its systemic absorption and preventing death if given soon enough after its ingestion. Both earths were found to be more effective than stomach wash out alone. Fuller's Earth (calcium montmorillonite, sub-bentonite) was the more efficient of the two and also more easily made into suspension. Kaolin, Decalso, and Amberlite had very little effect.

As a consequence of this work $300-\mathrm{g}$ packets of pure Fuller's Earth (Surrey finest powder, Laporte Industries Ltd.) sterilized at $150^{\circ} \mathrm{C}$ to kill spores are now stored in the factories where paraquat is manufactured. Recommendations for their use in human ingestion are also available for use by the nursing staff. Should treatment be required, one litre of water is to be added to one packet of Fuller's Earth and shaken for one minute to produce a suspension. After a stomach wash out, the suspension will be passed through the stomach tube, which will need to have a wide bore (for example, 30 F.G., 18 E.G.). In children, where a narrower tube has to be used, some dilution of the suspension will be necessary. As much as can be tolerated will be given. If there is likely to be any delay in arranging gastric lavage the patient is to be made to vomit, and then will be given the suspension to drink. Fuller's Earth has no toxic effect but, as it is not absorbed, bulky frequent motions occur after its use.

If there is doubt that paraquat has been absorbed, simple urine tests should be done during the 48 hours after the suspected absorption. To one of two $25 \mathrm{ml}$-samples of urine sufficient of a freshly made up $1 \%$ solution of sodium dithionite in $\mathrm{N} / 10$ sodium hydroxide is added to produce alkalinity (10 ml is usually adequate). The same quantity of $\mathrm{N} / 10$ sodium hydroxide is added to the second sample as a control. If paraquat is present an immediate colour change to green-blue is apparent. This test will detect paraquat down to a level of 1 p.p.m. $(0.1 \mathrm{mg} / 100 \mathrm{ml})$ in urine and, using normal instead of $N / 10$ sodium hydroxide, to about 10 p.p.m. (1 mg/100 $\mathrm{ml}$ ) in stomach contents. If the urine tests prove negative in the first 48 hours, it is quite definite that paraquat has not been absorbed in suffictent quantity to produce systemic after effects. If one is positive, timed urine samples for quantitative analysis should be collected as the amount of paraquat in urine over the first $\mathbf{4 8}$ hours provides a good indication of the ultimate prognosis.

So far Fuller's Earth suspension has only had to be given to a few men who thought that they could have been splashed in the mouth with paraquat liquor. They were given mouth washes of the suspension and some of it to drink. McGeown (personal communication) has used bentonite in two cases, but there was an interval of about two hours in each between the paraquat ingestion and its administration and both patients eventually succumbed. bentonite could absorb paraquat in the
Mr. R. J. Gow, A.R.I.C., Laboratory Manager, Imperial Chemical Industries Ltd., Widnes, developed the analytical test for paraquat. -I am, etc.,

T. D. BROWNE

Imperial Chemical Industries Ltd.,

P:lkington-Sullivan Works,

Widnes

1 Clark, D. G., British fournal of Industrial

\section{Brucellosis and Goat's Cheese?}

SIR,-Three middle-aged patients in our practice, Mr. and Mrs. A. and their friend, Mr. B., recently undertook a protracted tour of Spain. They drank sparingly of milk, which was always in cartons and presumably pasteurized. Mr. B., however, was fond of goat's cheese, which he ate frequently, a taste shared to a lesser extent by Mr. A. Mrs. A. took a monoamine oxidase inhibitor drug regularly and always abstained from all forms of cheese.

Two days before their return home Mr. A. became unwell and Mr. B. succumbed one week later; each developed a febrile illness. The diagnosis of brucellosis due to Brucella melitensis was eventually confirmed by blood culture in each case. Mrs. A. has remained well.

The circumstantial evidence from this controlled study indicting goat's cheese is strong and the moral evident.-We are, etc.,

A. M. W. PORTER E. L. SMITH

Camberley, Surrey

\section{The Ward Sister}

SIR,-Miss Pamela Jefferies's "Personal View" (7 August, p. 367) deserves to be read seriously by everyone concerned with nursing of patients in hospitals.

I wish to add a cogent reason to the very proper plea that nurses, like doctors, should be able to continue to advance in salary and position without abandoning the care of patients. The continuing advance in medical knowledge and techniques is reflected in the general acceptance that continuing education is essential. The advances in medical care involve new knowledge, skills, attitudes, and methods of thought in patient nursing. The continuing education of those who do nursing can only be done by people who are themselves practising and have special experience of older and newer skills of nursing.

We need to encourage the ward sisters who enjoy clinical nursing to stay on doing it. Miss Marjorie Mudge (7 August, p. 368) may feel that the nursing officer makes an "invaluable" contribution to in-service training but she must surely agree that it needs to be complemented by the invaluable contributions of someone who is au courant with the work. The only person who can be a satisfactory tutor for a ward sister asking for postgraduate education in modern methods is an experienced ward sister currently practising them. The nursing officer may for a few years after leaving the wards be able (in Miss Marjorie Mudge's phrase) to "act as a consultant in nursing practice." But however wise, within a few years she will of necessity become some- 